\title{
Aplicación de Instrumentos Internacionales de Derechos Humanos a las personas privadas de la libertad en Colombia
}

\section{Application of International Human Rights Instruments to persons deprived of their freedom in Colombia}

Autores: Luz Mireya Mendieta Pineda, Juliana Andrea Vargas Molina, Ana Isabel Mendieta Pineda

Mendieta Pineda, L.; Vargas Molina, J. y Mendieta Pineda, A. (2020). Aplicación de Instrumentos Internacionales de Derechos Humanos a las personas privadas de la libertad en Colombia. Revista Derecho y Realidad, 18, (35), 215-225. 


\section{APLICACIÓN DE INSTRUMENTOS INTERNACIONALES DE DERECHOS HUMANOS A LAS PERSONAS PRIVADAS DE LA LIBERTAD EN COLOMBIA*}

Application of International Human Rights Instruments to persons deprived of their freedom in Colombia

\section{Luz Mireya Mendieta Pineda' \\ Juliana Andrea Vargas Molina" \\ Ana Isabel Mendieta Pineda"}

Recepción: 12 de diciembre 2019

Aceptación: 13 de agosto 2020

\section{RESUMEN}

El presente artículo tiene como objetivo mostrar la forma en la cual el sistema penitenciario y carcelario de Colombia mantiene un estado de cosas inconstitucional, por la violación masiva de derechos fundamentales a los privados de la libertad. La metodología de investigación es documental y pretende, a través de la consulta doctrinaria, jurisprudencial y normativa, recoger datos sobre el tema que sustenta toda la información, para un análisis de aproximación al objeto de estudio y concluir sobre el incumplimiento al artículo 2.2 del Pacto Internacional de Derechos
Civiles y Políticos y la Convención Americana. Entre los hallazgos se destaca, que, pese a que el Estado colombiano ha firmado y ratificado tratados internacionales sobre derechos humanos y ha proferido normas internamente para su protección, existe una constante violación masiva de derechos fundamentales a las personas privadas de la libertad.

\section{PALABRAS CLAVES}

Instrumentos vulneración, derechos

internacionales, incumplimiento a tratados, privados de la libertad.

\footnotetext{
* Artículo de Investigación desarrollado en cooperación entre el "Grupo de investigación Derechos humanos y Medio ambiente", Reconocido y Clasificado en C COLCIENCIAS 2018 Universidad Pedagógica y Tecnológica de Colombia UPTC. Y el grupo de investigación "Fhiscis" Reconocido y Clasificado en COLCIENCIAS 2018 Universidad el Bosque, Bogotá. En el proyecto de investigación "Políticas públicas de igualdad ante el vacío en la jurisprudencia en la ejecución de la pena del juez competente".

I. Docente investigadora, titular de la Facultad de Derecho y Ciencias Sociales de la Universidad Pedagógica y Tecnológica de Colombia, abogada, especialista en instituciones jurídico-políticas. Magíster en Derecho Procesal de la Universidad Libre. Doctora en Derecho Penitenciario de la Universidad Libre. Investigación Código ORCID: 0000-0003-0371-5012. Email: luz. mendieta@uptc.edu.co

II. Estudiante de la Universidad Pedagógica y Tecnológica de Colombia, grupo de investigación Derechos Humanos y Medio Ambiente. Email: irusulitost@gmail.com

III. Abogada, Docente investigadora, asociada del Departamento de Humanidades de la Universidad del Bosque, Bogotá. Especialista en Derecho Constitucional, en Bioética y en filosofía de la ciencia, Magíster en Educación. Código ORCID: 00000002-2460-5800. Email: mendietaana@unbosque.edu.co
} 


\section{ABSTRACT}

The purpose of this article is to show how the Colombian prison and jail system maintains an unconstitutional situation, due to the massive violation of the fundamental rights of those deprived of their freedom. The research methodology is documentary and seeks, through doctrinal, jurisprudential and normative consultation, to gather data on the subject that supports all the information, for the analysis of the object of study and to conclude on the non-compliance with Article 2.2 of the International Covenant on Civil and Political Rights and the American Convention. Among the findings, it should be noted that, despite the fact that the Colombian State has signed and ratified international treaties on human rights and has issued internal regulations for their protection, there is a constant massive violation of the fundamental rights of persons deprived of their liberty.

\section{KEYWORDS}

International instruments, violation, human rights, non-compliance with treaties, deprived of liberty.

\section{INTRODUCCIÓN}

El presente artículo tiene como objetivo mostrar la forma en la cual el sistema penitenciario y carcelario de Colombia mantiene un estado de cosas inconstitucional por la violación masiva de los derechos fundamentales de los privados de la libertad. Ello se ha visto reflejado en las declaraciones de la Corte Constitucional por medio de las sentencias T-153 de 1998, T-388 de 2013 y T-762 de 2015.

En primer lugar, se abordarán algunos postulados desarrollados en artículos de instrumentos internacionales de declaraciones, convenciones y reglas. Los cuales, tratan la protección de derechos humanos, la cual ha sido suscrita $y$ ratificada por Colombia, su consagración y aplicación frente a la población privada de la libertad en país. En segundo lugar, se tratará la verificación del cumplimiento que hace el Estado colombiano a dichos postulados, consagrados en instrumentos internacionales, para luego verificar su incumplimiento a través de diferentes fallos de tutelas interpuestos por población privada de la libertad. Tal incumplimiento ha llevado a la Corte Constitucional, en tres oportunidades, a declarar el estado de cosas inconstitucional ante la violación masiva de derechos fundamentales a la población en cuestión.

\section{METODOLOGÍA}

Es documental y pretende, a través de la consulta doctrinaria, jurisprudencial y normativa, recoger datos sobre el tema que sustenta la investigación para un análisis de aproximación al objeto de estudio.

\section{Aporte de los Instrumentos Internacionales de DD. $\mathrm{HH}$ al Derecho penitenciario}

El propósito del siguiente artículo es realizar un breve estudio de la Declaración Universal de los Derechos Humanos, la Declaración americana de los derechos y deberes del hombre, la Convención Americana sobre Derechos Humanos, la Convención contra la tortura y otros tratos o penas crueles inhumanas o degradantes, las Reglas Nelson Mandela y las Reglas de Tokio 1990. Ello con el objetivo de extraer de sus artículos algunos postulados que garanticen los derechos humanos de los sujetos privados de la libertad, para luego, en la segunda parte del escrito, confrontarlos con la realidad que vive el sistema penitenciario y carcelario colombiano.

Los instrumentos internacionales son de gran valor para la humanidad, pues, en ellos se ha encontrado respaldo para que los Estados, que han acogido los DD. HH, no los quebranten y poder hacer efectivo en forma individual o colectiva los derechos. Los tratados formales que han sido ratificados por los Estados o a los que se han adherido, así como el derecho internacional consuetudinario, poseen carácter vinculante (Oficina del Alto Comisionado de las 
Naciones Unidas, 2016). Tanto el artículo 2.2 del Pacto Internacional de Derechos Civiles y Políticos (PIDCP, 1966) como el artículo 2 de la Convención Americana, señalan la obligación positiva de los Estados Partes de adoptar, con arreglo a sus procedimientos constitucionales y a las disposiciones del Pacto y/o de la Convención, las medidas legislativas que son necesarias para hacer efectivos los derechos (Organización de las Naciones Unidas, 1966).

En el supuesto de que los Estados justifiquen el incumplimiento de estos deberes, sobre la base de la legislación nacional, se comprometería su responsabilidad internacional. Ya que, según el artículo 27 de la Convención de Viena sobre el Derecho de los Tratados de 1969: "Una parte no podrá invocar las disposiciones de su derecho interno como justificación del incumplimiento de un tratado, principio de primacía del derecho internacional sobre el derecho interno" (Art. 27, 1980, p. 13). Concretamente, la Corte Interamericana de Derechos Humanos ha señalado en su numeral 37 que: "Son muchas las maneras como un Estado puede violar un tratado internacional y, específicamente, la Convención". Con respecto al último caso, puede hacerlo, por ejemplo, omitiendo dictar las normas a que está obligado por el artículo 2.2 del Pacto Internacional de Derechos Civiles y Políticos. También, por supuesto, dictando disposiciones que no estén de conformidad con lo que de él exigen sus obligaciones dentro de la Convención, con ciertas atribuciones de la Comisión Interamericana de Derechos Humanos (Corte Iberoamericana de Derechos Humanos, 1993).

A continuación, examinaremos algunos documentos ya enunciados.

\section{Declaración Universal de los Derechos Humanos}

Como consecuencia de la segunda guerra mundial, nace, en 1945, la Organización de las Naciones Unidas [ONU], cuya Asamblea General adopta y expide la Declaración de los Derecho Humanos el 10 de diciembre de 1948. Su fin primordial es salvaguardar las generaciones futuras de los posibles conflictos de carácter internacional. En donde desarrolla diversos derechos humanos inherentes a las personas, en cualquier espacio temporal y geográfico del mundo, por medio de la guía de una hoja de ruta que permite garantizar dichos derechos (ONU, 1945).

De aquellos 30 artículos, que son de aplicación general sin excepción de ninguna clase, sólo se pretende enunciar algunos para confrontarlos más adelante con la realidad de lo que sucede en el sistema penitenciario y carcelario de Colombia. Entre ellos se encuentran: art. 1 Igualdad y libertad, art. 3 derecho a la vida, art. 5 la prohibición de la tortura, penas o tratos crueles, inhumanos o degradantes, art. 7 igualdad ante la ley, art. 10 publicidad del proceso con un juez independiente e imparcial, art. 11 presunción de inocencia, art. 19 libertad de opinión y de expresión. Todos ellos recogidos en la Constitución Nacional, en el código penal, en el código de procedimiento penal y en el código penitenciario y carcelario. Pese a su positivización, los sujetos privados de la libertad luchan por su aplicación, generalmente, a través de la acción de tutela como el medio más expedito para obtener su cumplimiento.

\section{Declaración Americana de los derechos y deberes del hombre}

Aprobada en la Novena Conferencia Internacional Americana. Bogotá, Colombia, 1948. En su preámbulo trata de recoger los derechos que busca proteger:

Todos los hombres nacen libres e iguales en dignidad $\mathrm{y}$ derechos $\mathrm{y}$, dotados como están por naturaleza de razón y conciencia, deben conducirse fraternalmente los unos con los otros. La protección la desarrolla en los arts. 1 derecho a la vida, a la libertad; el art. 2 derecho de igualdad; el art. 11 derecho a la salud; art. 12 derecho a la educación; art. 14 derecho al trabajo y art. 24 derecho de petición. (Comisión 
Interamericana de Derechos Humanos, 1948)

Al igual que los derechos mencionados, según Salvioli (2003), la Declaración también aporta "el fundamento de los derechos humanos" y su universalidad (p. 3). "La inobservancia por parte de los Estados que la han suscrito y ratificado genera responsabilidad internacional como también violación al principio de buena fe en el cumplimiento de las obligaciones internacionales" (p. 14).

\section{Convención Americana sobre Derechos Humanos o Pacto de San José}

La Convención Americana sobre Derechos Humanos, también llamada "Pacto de San José", fue suscrita en San José de Costa Rica el 22 de noviembre de 1969, entró en vigor el 18 de julio de 1978, ratificada por Colombia el 28 mayo de 1973. El texto de la Convención Americana consagra derechos civiles y políticos, dentro de los que se destacan: el derecho a la vida, a la integridad personal, a la libertad personal, a las garantías judiciales, a la legalidad. Igualdad ante la ley y protección judicial (Convención Americana sobre Derechos Humanos, 1978).

$\mathrm{Su}$ importancia se encuentra en reafirmar los valores filosóficos y jurídicos de la Declaración Universal de los Derechos Humanos, la obtención y el mantenimiento de la dignidad de la persona para alcanzar la satisfacción de las necesidades del hombre (Melet y Melet, 2007).

\subsection{Convención contra la tortura y otros tratos o penas crueles inhumanas o degradantes}

Adoptada y abierta a la firma el 10 de diciembre de 1984 y entra en vigor el 26 de junio de 1987, se define la tortura como:

[...] todo acto por el cual se inflija intencionadamente a una persona dolores o sufrimientos graves, ya sean físicos o mentales, con el fin de obtener de ella o de un tercero información o una confesión, de castigarla por un acto que haya cometido, o se sospeche que ha cometido, o de intimidar o coaccionar a esa persona o a otras, o por cualquier razón basada en cualquier tipo de discriminación, cuando dichos dolores o sufrimientos sean infligidos por un funcionario público u otra persona en el ejercicio de funciones públicas, a instigación suya, o con su consentimiento o aquiescencia. No se considerarán torturas los dolores o sufrimientos que sean consecuencia únicamente de sanciones legítimas, o que sean inherentes o incidentales a éstas. (Párr. 1 del art. 1)

De acuerdo con Varela (1994), "La prohibición de la tortura pertenece al jus cogens, es una obligación internacional dirigida a proteger al ser humano" (p, 107), "Quien viole está prohibición es responsable ante la comunidad internacional" (p.108). Por lo tanto, los Estados deben consagrarla como una prohibición en la Carta Política y como una conducta punible en el código penal, puesto que, la tortura no halla justificación alguna en ninguna circunstancia.

\section{Reglas Nelson Mandela}

Dichas reglas son, como su nombre lo menciona, un homenaje a Nelson Mandela quien estuvo privado de su libertad por 27 años. Son normas adoptadas por las Naciones Unidas en 1955, tuvieron su última reforma el 17 de diciembre de 2015. Establecen nuevos estándares para el tratamiento de la población privada de la libertad con principios y prácticas que se reconocen como idóneas para el tratamiento de reclusos. Se encuentra estructurado en dos partes, la primera contiene: i) principios fundamentales, ii) gestión de los expedientes de los reclusos en el que trata de la separación por categorías, alojamiento, higiene personal, ropas, cama, alimentación, ejercicio físico y deporte, servicios médicos, restricciones, disciplina, sanciones, instrumentos de coerción física, registro de reclusos, celdas, información, 
derecho de queja de los reclusos, contacto con el mundo exterior, biblioteca, religión, depósito de objetos pertenecientes a los reclusos, notificaciones, investigaciones, traslado de reclusos, personal penitenciario e inspecciones internas y externas (Oficina de las Naciones Unidas Contra las Drogas y el Delito, 1955).

La segunda parte de las reglas se encuentra dirigida a categorías especiales conformadas por la siguiente estructura: i) principios rectores; ii) tratamiento, clasificación e individualización, beneficios, trabajo, instrucción, recreo, relaciones sociales y ayuda post penitenciaria; iii) reclusos con discapacidades o enfermedades mentales; iv) personas detenidas o en espera de juicio; v) personas encarceladas por causas civiles; vi) personas detenidas o encarceladas sin imputación de cargos (UNODC, 1955).

Las Reglas Mínimas de las Naciones Unidas para el Tratamiento de los Reclusos han tenido influencia en las políticas criminales y en el desarrollo de las leyes de los países que las han suscrito.

\section{Reglas de Tokio 1990}

Las Reglas de Tokio son las llamadas reglas mínimas de las Naciones Unidas para aplicación de medidas no privativas de la libertad, medidas que fueron adoptadas por la Asamblea General en la Resolución 45/110 del 14 de diciembre de 1990. Las reglas mínimas contienen recomendaciones para disminuir la prisión, partiendo de que el encarcelamiento debe ser el último recurso por aplicar. Contiene normas relativas a la aplicación de medidas no privativas de la libertad, la formulación de políticas entre otros, cuyo fin es impulsar las medidas sustitutivas del encarcelamiento (UNODC, 2010 , p. 13), tal y como ha sido planteado por la Corte Constitucional en sus Sentencias T-388 de 2013 y T-762 de 2015.

\section{El desafío del Estado Colombiano en el cumplimiento de los instrumentos Internacionales}

La Constitución Nacional ha recogido, en su articulado, los postulados de las Declaraciones, Convenciones y Reglas, en sus artículos: 11 (derecho a la vida), 13 (derecho a la libertad e igualdad ante la ley), 16 (derecho al libre desarrollo de la personalidad), 18 (libertad de conciencia), 25 (derecho al trabajo), 28 (derecho a la libertad personal) entre otros. Los cuales son aplicables a todos los sujetos, sin excepción.

Ahora, con respecto a las condiciones carcelarias que se deben tener en cuenta en pro de garantizar los derechos de las personas recluidas, la Corte Interamericana de Derechos Humanos incorporó en su jurisprudencia los principales estándares sobre condiciones carcelarias y el deber de prevención que el Estado debe garantizar en favor de los privados de libertad. Se pueden sintetizar así:

i) Prohibición del hacinamiento; ii) separación de condenados y procesados; iii) acceso al agua potable; iv) buena calidad en la alimentación, con los nutrientes suficientes; v) salud $y$ tratamientos adecuados; vi) educación, trabajo y recreación son funciones y deben ser brindadas a todas las personas privadas de libertad; vii) garantizar las visitas; vii) las celdas con luz natural o artificial, ventilación e higiene; ix) los servicios sanitarios en condiciones de higiene y privacidad; $x$ ) estándares mínimos para que se respete la dignidad humana; y xi) Las medidas disciplinarias no pueden poner en peligro la salud física o mental del recluso. (Cuadernillo de Jurisprudencia No. 9, 2016)

En suma, la normatividad internacional interna, la jurisprudencia de la Corte Interamericana de Derechos Humanos y la Corte Constitucional, como se mencionó en los subtítulos y párrafos anteriores, establecen disposiciones para proteger los derechos humanos de las personas privadas de la libertad. Sin embargo, la concesión de tutelas amparando a dichos sujetos y protegiendo sus derechos fundamentales advierten las dificultades que tiene el Estado para garantizar sus derechos. Así, es posible 
afirmar la forma en la cual los derechos humanos son inherentes al ser humano, y negar un derecho produce un impacto negativo en otros (Sentencia T-049, 2016). Si bien es cierto, que los sujetos privados de la libertad tienen limitaciones, estas deben ser las mínimas necesarias, de lo contrario será un exceso que genera violación a los derechos (Sentencia T-143, 2017). Los internos no tienen derechos de menor categoría, simplemente algunos están suspendidos o restringidos, mientras que existen otros que deben permanecer de manera irreductible (Sentencia T-190, 2000). Por lo tanto, debe ser protegido y respetado como cualquier otra persona (Sentencia T-232, 2017), siendo una necesidad "eliminar la perniciosa justificación del maltrato carcelario que consiste en aceptar como válida la violación del derecho cuando se trata de personas que han hecho un mal a la sociedad" (Sentencia $\mathrm{T}-596,1992)$.

Como se mencionó en la primera parte del presente artículo, a la luz de los documentos internacionales que se han referenciado, como también los estándares mencionados por la Corte Interamericana de Derechos Humanos, es posible advertir en los párrafos siguientes si se da la protección de los derechos ya mencionados a los privados de la libertad de acuerdo con la información extraída de sentencias de tutelas, y algunos informes, que nos aproximen al objeto de estudio.

La Corte Constitucional reconoce que el hacinamiento carcelario ha estado presente en la mayoría de los centros penitenciarios y carcelarios de Colombia, identifica que las poblaciones carcelarias sometidas a condiciones de hacinamiento se les impide la resocialización y no pueden gozar de una vida digna. Lo cual, desvirtúa los fines del tratamiento penitenciario, impide la separación de los internos, impera la violencia, la extorsión, la corrupción y genera violación masiva de derechos fundamentales (Sentencia T-153, 1998).

El hacinamiento carcelario en 1998 bordeó el 34\% y llevó a que por primera vez la Corte Constitucional declarara el estado de cosas inconstitucional mediante Sentencia T-153 de 1998. La cual, prácticamente, se mantuvo en los años subsiguientes, en algunos disminuyendo $y$ en otros aumentando. Sin embargo, fue en el año 2011 que se acentuó y se extendió el hacinamiento en la mayoría de los centros penitenciarios y carcelarios de Colombia, promediando el $50 \%$ en forma general y hasta la fecha (2020). Ello resulta en la violación masiva de derechos fundamentales, que ha llevado a que la Corte Constitucional en dos oportunidades, a través de las Sentencias T-388 de 2013 y T-762 de 2015, a declarar el estado de cosas inconstitucional.

En el año 2014 se expide la Ley 1709, cuyo objetivo era alcanzar la disminución del hacinamiento carcelario. Para ello amplió el aspecto objetivo de los subrogados penales y de la pena sustitutiva de prisión domiciliaria, esto es: i) la suspensión de la ejecución de la pena paso de 3 a 4 años, ii) la libertad condicional que estaba en las $2 / 3$ partes la amplió a las $3 / 5$ partes iii) la prisión domiciliaria que se encontraba en 5 años pasó a 8 años (Ley 1709, 2014).

Dichas medidas fueron bien recibidas por la población condenada privada de la libertad. Sin embargo, un año después y con el hacinamiento carcelario y penitenciario bordeando el $50 \%$ con las implicaciones que acarrea, principalmente la violación masiva de derechos fundamentales, por tercera vez la Corte decreta el estado de cosas inconstitucional en Sentencia T-762 de 2015.

En la sentencia, la Corte describió cinco dificultades estructurales que consideró las causa de la vulneración constante y sistemática de los derechos del recluso, los cuales identificó como:

(i) Falencias en la política criminal; (ii) hacinamiento; (iii) dificultades en la prestación del servicio de salud; (iv) reclusión en un mismo lugar de personas sindicadas y condenadas; y (v) las condiciones de higiene y salubridad, que son indignas en la mayoría de los establecimientos penitenciarios. (Sentencia T-762, 2015). 
El hacinamiento carcelario propicia la violencia, la escases de bienes básicos, impacta sobre la dignidad humana, la posibilidad de que se den tratos crueles, inhumanos e indignos, por lo cual La Comisión de Seguimiento de la Sentencia T-388 de 2013, de la que hace parte Dejusticia y otras organizaciones, concluyó "que la violación masiva y generalizada de los derechos de las personas privadas de la libertad persiste, y el Estado debería implementar una estrategia para reformar la política criminal y las prácticas inconstitucionales que presentan en las cárceles colombianas" (Dejusticia, 2018). Asimismo, se presentan afectaciones relacionadas con las condiciones de reclusión a las que, sindicados y condenados, son sometidos, como lo es la reclusión conjunta entre condenados y sindicados, las fallas en la prestación de los servicios de salud en el sector penitenciario y carcelario, la precariedad de la alimentación suministrada y las condiciones inhumanas de salubridad e higiene de los establecimientos de reclusión, entre otras, son las que afectan los derechos del privado de la libertad (Sentencia T-762, 2015). En varios centros carcelarios no existen lugares dignos donde dormir, comer, tener visitas conyugales e íntimas, ejercer actividades de recreación, de formación y de resocialización (Sentencia T-762, 2015).

El 28 de agosto de 2018, La Comisión Interamericana de Derechos Humanos admitió una demanda interpuesta por defensores de derechos de Medellín, en la que se solicitó intervención para que el Estado adopte medidas urgentes que permitan mejorar la grave crisis que viven los centros carcelarios y penitenciarios de Antioquia y del país (Carmona, 2018). De igual forma, la grave situación carcelaria que hoy horroriza a la población reclusa, sin que se vea una solución a corto plazo, lleva a que el Estado deba, igualmente, responder (El Tiempo, 2016), por esas violaciones que están en cabeza de sus funcionarios públicos.

El presente panorama de los centros penitenciarios y carcelarios del país parece no tener solución, pese a las tres sentencias de la Corte Constitucional que han declarado el estado de cosas inconstitucional y los autos de seguimiento (Auto 121 de 2018 y Auto 110 de 2019). La situación es más grave que la estudiada en el año de 1998 cuando la Corte declaró, por primera vez, el estado de cosas inconstitucional fundamentado en la violación masiva de derechos fundamentales y el desconocimiento de los postulados de la Constitución Nacional como de los tratados que ha suscrito y ratificado el Estado colombiano en tal ámbito.

El 21 de marzo de 2020, los privados de la libertad de las cárceles de Bogotá, Jamundí, Cómbita e Ibagué entraron en protestas por la crisis del coronavirus, se presentaron protestas e incendios (El Espectador, 2020) que terminaron en enfrentamientos entre presos y guardianes, con un resultado de 83 heridos y 23 muertos. Adicionalmente, existieron riñas entre los mismos presos (El Tiempo, 2020). Pese a las medidas que se tomaron, a través del Decreto 546 del 2020, persiste el hacinamiento y con ello la fácil propagación del virus dado a los ambientes propicios, como la precariedad del agua, escasez elementos aseo y la imposibilidad de acceder a la salud, colocando en peligro la vida e integridad de los 120.242 reclusos privados de la libertad al 8 de mayo. (González, 2020).

Por último, han transcurrido 29 años de haberse expedido la Carta Política, se han suscrito varios tratados, convenios, pactos, reglas. Se ha declarado, en 3 oportunidades, el estado de cosas inconstitucional de los centros penitenciarios y carcelarios. Sin embargo, no se ha presentado una reducción de la situación de deshumanización y violación a los derechos humanos de los privados de la libertad.

\section{CONCLUSIONES}

El Estado colombiano ha suscrito $y$ ratificado la mayoría de los instrumentos internacionales que tratan los derechos humanos, acogiéndolos en su normatividad interna. Sin embargo, la afectividad de los mismos con respecto a los sujetos privados de la libertad es contraria, dado que viola e incumple lo dispuesto en el artículo 2.2 del PIDCP, y la Convención Americana, y hace 
que el Estado colombiano incumpla las obligaciones adquiridas sobre la protección de los derechos.

La violación masiva de derechos fundamentales del privado de la libertad es una constante, mediante la cual el Estado colombiano compromete su responsabilidad internacional al evadir lo dispuesto en la Declaración Universal de los Derechos Humanos, la Declaración Americana de Derechos Humanos, la Convención Americana de Derechos Humanos, la Convención contra la tortura, las Reglas Nelson Mandela y las Reglas de Tokio.

\section{BIBLIOGRAFÍA}

» Carmona, J. (2018). Buscan apoyo internacional para resolver crisis carcelaria en el país. Con la demanda ante la CIDH, defensores de derechos humanos de Medellín quieren cambiar la situación. El Tiempo: Recuperado de https://www. eltiempo.com/colombia/medellin/buscan-apoyo-en-la-cidh-para-resolver-crisiscarcelaria-en-antioquia-261430.

» Comisión Interamericana de Derechos Humanos (1948). Declaración Americana de los Derechos y Deberes del Hombre. Aprobada en la Novena Conferencia Internacional Americana. Bogotá: Recuperado de http://www.oas.org/es/cidh/ mandato/Basicos/declaracion.asp

» Congreso de la República de Colombia (20 de enero de 2014). Ley 1709. Ley ordinaria. Diario Oficial 49039, Bogotá.

» Congreso de la República de Colombia (2018 - 2019). Auto 121 de 2018 y Auto 110 de 2019). Marco del seguimiento unificado a las Sentencias T-388 de 2013 y T-762 de 2015. [ MP. Gloria Stella Ortiz Delgado]

» Convención Americana sobre Derechos Humanos. (1978). Pacto de San José. Gaceta Oficial No. 9460 del 11 de febrero de 1978: Recuperado en https://www. oas.org/dil/esp/1969_Convenci\%C3\%B3n_Americana_sobre_Derechos_Humanos.pdf.

» Corte Constitucional de Colombia (07 de marzo de 2017). Sentencia T-143. [MP. María Victoria Calle Correa].

» Corte Constitucional de Colombia (10 de diciembre de 1992). Sentencia T-596. [MP. Ciro Angarita Barón].

» Corte Constitucional de Colombia (10 de febrero de 2016). Sentencia T-049. [MP. Jorge Iván Palacio Palacio].

» Corte Constitucional de Colombia (16 de diciembre de 2015). Sentencia T-762. [MP. Gloria Stella Ortiz Delgado].

» Corte Constitucional de Colombia (20 de abril de 2017). Sentencia T-232. [MP. María Victoria Calle Correa]

$»$ Corte Constitucional de Colombia (28 de abril de 1998). Sentencia T-153. [MP. Eduardo Cifuentes Muñoz]

» Corte Constitucional de Colombia (28 de febrero de 2000). Sentencia T-190. [MP. José Gregorio Hernández Galindo]

" Corte Constitucional de Colombia (28 de junio de 2013). Sentencia T-388. [MP. María Victoria Calle Correa]. 
» Corte Interamericana de los Derechos Humanos (2016). Cuadernillo de Jurisprudencia No. 9. Personas privadas de libertad. Recuperado de http://www.corteidh.or.cr/sitios/libros/todos/docs/privados9.pdf.

» Dejusticia (14 de agosto de 2018). Política carcelaria en Colombia sigue siendo insostenible. Derecho-Justicia y Sociedad. Recuperado de https://www.dejusticia. org/politica-carcelaria-en-colombia-aun-es-insostenible-comision-de-seguimiento-a-crisis-del-sistema-penitenciario-y-carcelario/.

» El Espectador (21 de marzo de 2020). La cárcel La Modelo en estado de alerta máxima. Disturbios en diferentes cárceles de Colombia. Redacción Judicial. Recuperado de https://www.elespectador.com/noticias/judicial/disturbios-en-diferentes-carceles-de-colombia-articulo-910589/.

» El Tiempo (22 de marzo de 2020). Tras enfrentamientos hay 23 muertos y 83 heridos en cárcel La Modelo. Nueve guardianes del INPEC resultaron heridos. Hubo disturbios en 13 cárceles del país. Justicia. Recuperado de https://www.eltiempo.com/justicia/investigacion/heridos-y-fallecidos-tras-amotinamiento-encarceles-del-pais-475872.

» El Tiempo. (2016). El hacinamiento en las cárceles de Colombia va de mal en peor. Por cada nuevo cupo que se crea en una cárcel colombiana, llegan tres reclusos. Especiales. Recuperado de https://www.eltiempo.com/multimedia/especiales/hacinamiento-en-carceles-de-colombia/16549364/1/.

» González, P. L. (2020). La crisis carcelaria en el marco del Covid-19. NODAL Temas. Recuperado de https://www.nodal.am/2020/05/colombia-la-crisis-carcelaria-en-el-marco-del-covid-19-por-leonardo-gonzalez-p/.

» Melet, P, A. y Melet, P. A. (2007). La Convención Americana sobre Derechos Humanos o Pacto de San José: Su influencia en el ordenamiento jurídico interno venezolano. Revista de la Facultad de Ciencias Políticas no. 3, 2007, pp. 117-137, Recuperado de http://servicio.bc.uc.edu.ve/derecho/revista/3-2007/art\%204.pdf.

» Oficina de las Naciones Unidas Contra las Drogas y el Delito (1955). Reglas Mínimas de las Naciones Unidas para el Tratamiento de los Reclusos: Reglas Nelson Mandela. Recuperado de: https://www.unodc.org/documents/justice-and-prison-reform/GA-RESOLUTION/S_ebook.pdf.

» Oficina contra la Droga y el Delito Viena (2010). Pacto de Viena. Manual de principios básicos y prácticas prometedoras en la aplicación de Medidas sustitutivas del encarcelamiento: Serie de manuales de justicia penal. p. 13. Naciones Unidas. Recuperado de: https://www.wipo.int/export/sites/www/wipolex/es/ glossary/vienna-convention-es.pdf.

» Oficina del Alto Comisionado de las Naciones Unidas para los Derechos Humanos (2016). Los principales tratados. Naciones Unidas. Nueva York y Ginebra. Recuperado de: https://www.ohchr.org/documents/publications/coretreatiessp. pdf.

» Organización de las Naciones Unidas (1945). La Organización. Recuperado de: https://www.un.org/es/about-un/.

» Organización de las Naciones Unidas (1966). Pacto Internacional de Derechos Civiles y Políticos. Adoptado y abierto a la firma, ratificación y adhesión por la Asamblea General en su resolución 2200 A (XXI), de 16 de diciembre de 1966. Recuperado de: https://www.ohchr.org/sp/professionalinterest/pages/ccpr.aspx.

Salvioli, F. O. (2003). El aporte de la Declaración Americana de 1948 para la 
protección internacional de los derechos humanos. El sistema interamericano de protección de los derechos humanos en el umbral del Siglo XXI.

» Varela, L. A. (1994). La tortura; y, otros tratos y penas crueles inhumanas o degradantes. Revista de Ciencias Jurídicas, núm. 77. 